\title{
LAS ACEPCIONES DEL NAHUATLISMO TEPUZQUE EN EL ESPAÑOL DE MÉXICO
}

\author{
THE MEANINGS OF \\ THE NAHUATLISMO \\ TEPUZQUE IN THE \\ SPANISH OF MEXICO
}


El presente artículo investiga el caso de la palabra tepuzque (cobre en náhuatl) como un ejemplo de préstamo transitorio en el habla de los conquistadores españoles. En él, se estudian, a través del testimonio de Bernal Díaz del Castillo, que las registró en su crónica, acepciones que no están incluidas en ninguno de los diccionarios de mexicanismos actuales. Para detallar los referentes de dichas acepciones, se incluye información histórica sobre las monedas y los cañones en el siglo XVI (tepuzques para los españoles), y, en la segunda parte, se lleva a cabo un análisis lingüístico sobre los cambios fonéticos, morfológicos y semánticos que sufrió la palabra primero como préstamo del náhuatl al español y después a las relaciones semánticas entre las acepciones que tuvo en español.

Palabras ClaVe: tepuzque, indigenismos, préstamos, monedas, cañones

This article investigates the case of the word tepuzque (copper in nahuatl) as an example of a transitional loan in the speech of the Spanish conquistadors. It explores, through the testimony of Bernal Díaz del Castillo, meanings which he recorded in his Chronicle that are not registered in any of the current dictionaries of mexicanismos. To detail the references of these meanings, the article includes in the first part historical information about coins and cannons in the sixteenth century (tepuzques for Spaniards), and, in the second part, a linguistic analysis is carried out focused on phonetic, morphological and semantic changes that the word suffered first as a nahuatl loan to Spanish and then the semantic relationships between its meanings in Spanish.

KeYwORDs: tepuzque, indigenismos, loans, coins, cannons

FECHA DE RECEPCión: 04/11/2015

FECHA DE ACEPTACIÓN: 17/02/2016 


\section{LAS ACEPCIONES \\ DEL NAHUATLISMO TEPUZQUE \\ EN EL ESPAÑOL DE MÉXICO ${ }^{1}$}

\section{THE MEANINGS \\ OF THE NAHUATLISMO TEPUZQUE IN THE SPANISH OF MEXICO}

Agustín Rivero Franyutti

Universidad Autónoma del Estado de Morelos

\section{Presentación}

Decir que en el ámbito de la lexicografía hispánica los diccionarios comunes ${ }^{2}$ (semasiológicos y sincrónicos) van a la zaga con respecto al uso de las palabras en español es rozar el lugar común. No obstante, este hecho es lo que ha justificado la aparición de otro tipo de diccionarios, los llamados manuales o de uso, que pretenden llenar ese vacío recogiendo

\footnotetext{
${ }^{1}$ En el XVI Congreso Internacional de la Asociación de Lingüística y Filología de América Latina, que se llevó a cabo en Alcalá de Henares, España, del 6 al 9 de junio de 2011, leí, en apretados 15 minutos, una versión resumida de este texto que después se publicó en la recopilación de actas del congreso. La versión que presento aquí está muy ampliada con respecto a esa y presenta un orden diferente en los apartados que lo componen. Esto con el propósito de adaptar un texto leído en voz alta a los requerimientos de un trabajo académico de investigación que está destinado a difundirse por medio de la escritura.

${ }^{2}$ Se entiende que son "comunes" porque, desde el último tercio del siglo xx, comenzaron a diferenciarse de otros tipos de diccionarios al partir de una "sincronía práctica" que no debe exceder el periodo de vida promedio de un hablante, y porque parten de las necesidades básicas de los usuarios típicos: encontrar el significado de un significante conocido y resolver dudas sobre la ortografía de una palabra.
} 
en sus páginas el léxico que los hablantes emplean actualmente en alguna región o país de lengua española. Sobre ellos afirma Manuel Seco:

Los diccionarios manuales se proponen incluir todo lo que a su juicio está vivo en el momento presente (sin especificar nunca cuál es la extensión de ese presente, su sincronía práctica), y excluyen todo lo que a su juicio no lo está. Las notables diferencias con que se realiza este propósito en unos diccionarios y otros radican en esa variable tan poco objetiva de su juicio $^{3}$ (2003: 72).

Por eso, no resulta extraño observar que, si uno busca la palabra tepuzque en los diccionarios de mexicanismos (que pueden considerarse, grosso modo, como diccionarios de "uso" regional), ${ }^{4}$ lo que encuentra, como acepción primera, y generalmente única, es la referida a las monedas de baja ley, que, desde los primeros años de la colonización española en México, se acuñaron a partir de una liga de oro con cobre. Incluso los nueve ejemplos que registra el CORDE están usados en este sentido.

Sin embargo, Bernal Díaz del Castillo escribió en su Historia verdadera de la conquista de la Nueva España que también a algunos cañones se les llamaba tepuzques y que a ciertas personas de bajo nivel social que pretendían pasar por aristócratas o acaudalados se les aplicaba la locución “de

\footnotetext{
${ }^{3}$ Las cursivas finales son del autor de la cita.

${ }^{4}$ Alguno incluso puede considerarse como histórico. Por ejemplo, el Diccionario de mejicanismos (1992), de Francisco J. Santamaría, que recoge mexicanismos usados en obras literarias del pasado.
} 
tepuzque" ("fulano de tepuzque") para señalar la "impureza" de sus aspiraciones sociales.

Además de los usos documentados por Bernal Díaz, aparece, desde el español colonial, la palabra tepuzque en la formación de algunos topónimos de poblaciones que se encuentran tanto en México como en los Estados Unidos.

De todo lo dicho, se sigue que el propósito de este artículo es mostrar los usos que la palabra tepuzque tenía en el español coloquial mexicano de la colonia que no están documentados en los principales diccionarios de mexicanismos, y, también, su uso en la formación de topónimos que hoy siguen usándose. Para lograr esto, he dividido el contenido en dos partes: la primera consiste en una descripción histórica que nos ayuda a situar en su contexto los referentes de las distintas acepciones de la palabra, y la segunda es una presentación de las diferentes acepciones de tepuzque que parten de su estatus como préstamo, con todas las implicaciones semánticas y morfológicas que eso conlleva, para mostrar la aparición de este término en el español de los conquistadores en tierras mexicanas.

\section{Sobre las monedas}

Al peso llamado de tepuzque le corresponde la poco honrosa reputación de haber sido la primera moneda de oro acuñada en América, porque en realidad no fue de oro puro ni tampoco una moneda en sentido estricto. ${ }^{5}$ Esa, la verdadera,

\footnotetext{
5 "But the first gold coin minted in the New World is not the true "first gold
} 
es la de dos escudos, producida en Cartagena en 1622, de la que solo se conocen cinco piezas en el mundo actual. ${ }^{6}$ (Sedwick: 1).

La poca moneda de España que llegó al continente americano determinó que en los primeros tiempos de la conquista (alrededor de 1520) los españoles recurrieran al uso de pequeños pedazos de oro y plata que se conocieron como tejos o tejuelos, y que eran trozos irregulares, cortados de piezas ornamentales o de lingotes, con distintas marcas de su peso estampadas por los oficiales reales. Con el tiempo, las marcas se fueron alterando, así como la pureza de los metales, pues, para compensar la poca cantidad de oro que había, comenzaron a agregarle cobre para mantener el peso de la moneda y el poder adquisitivo. Los indígenas, cuando se dieron cuenta del engaño, llamaron a las monedas tepuzque o sea 'moneda despreciable'.

Estas piezas, si bien estaban documentadas en las relaciones históricas, no se habían visto hasta que en 1992 unos buzos encontraron el naufragio de un barco que se hundió frente a la isla de Gran Bahama. ${ }^{7}$ De ahí recuperaron unos

coin". That distinction belongs to the gold pieces cut from cast gold bars made from Native American artifacts, melted down at the time of the Conquest (circa 1520)" (Sedwick: 1).

6 "One of these, supposedly the finest of the five, will be auctioned in March (couple of years ago - BR) as part of the Norweb Collection, and its conservative estimate Is $\$ 15,000$ - $\$ 25,000$ ” (Sedwick: 1 ).

7 "Until recently, no tejuelos de tepuzque were known to have survived the recall. The first of these surviving rarities, also from the "Tumbaga wreck", surfaced in the original 1993 Christie's sale in London, but no one recognized them for what they were. Outside the auction Dr. Frank Sedwick and his son Daniel Sedwick, also a professional numismatist specializing in Spanish colonial and shipwreck coinage and artifacts, acquired what they considered the best of the known cut 
lingotes de oro y plata, "produced a number of silver and gold ingots - all more or less adulterated with copperwhose markings indicated they were cast in Mexico in the 1520s" (Sedwick: 1). Además, encontraron 10 piezas de oro, de las cuales, la que más se asemejaba a una moneda,

it is nearly exactly pentagonal in shape, about $7 / 8$ " in diameter, and about 1/4" thick, with sloping sides and both markings on top, 23.8 grams in weight. Furthermore, this appears to be one of the purest of the ten tepuzque gold "coins," as most of the others show a lot of copper color (one is clearly marked “VIIII” for 9 karat!) (Sedwick: 1).

A este oro adulterado es al que se refiere Bernal Díaz cuando narra (1977, II: 74) que a causa de las muchas deudas que habían adquirido las tropas de Cortés por la compra de armas y medicinas para la conquista

...todo el oro que se fundió echaron tres quilates más de lo que tenía de ley, porque ayudasen a las pagas, y también porque en aquel tiempo habían venido mercaderes y navíos a la Villa Rica, y creyendo que en echar los tres quilates más ayudaban a la tierra y a los conquistadores; y no nos ayudó en cosa ninguna, antes fue en nuestro perjuicio, porque los mercaderes, viendo que para los tres quilates saliese a la cabal de sus ganancias, cargaban en las mercaderías y cosas que vendían cinco quilates más, y de esta manera anduvo el oro de tres quilates más cinco o seis años, y a este respecto

gold pieces: a pentagonal chunk with all the prescribed markings bold and full, including a crowned "C" for King Charles" (García-Barneche, 2010: 24). 
se nombraba el oro de quilates tepuzque, que quiere decir en lengua de los indios cobre; y ahora tenemos aquel modo de hablar...

Aunque, como recuerda Clarence Haring (1975: 287), la posibilidad de fundar casas de moneda estaba ya contemplada en las Instrucciones que los Reyes Católicos dieron a Colón con fecha del 23 de abril de 1497, la verdad es que el intercambio comercial en los primeros tiempos de las colonias españolas en América, tanto en las islas como en tierra firme, fue bastante caótico: desde el trueque en especie de productos como el cacao o el algodón hasta el uso de oro y plata por su peso, de donde proviene la palabra tan extendida en América para denominar la unidad monetaria corriente.

Durante ese periodo inestable que fue la conquista de los territorios ocupados por los aztecas y los tarascos, los españoles pusieron en marcha casas de fundición donde aprovecharon la habilidad de los experimentados orfebres de Azcapotzalco. ${ }^{8}$ Estos primeros experimentos les ayudaron a establecer más adelante otras casas de fundición más complejas. Latécnica empleada en estas casas consistía en el uso de:

canes to blow into a pot in order to reach the proper temperature to melt the metal and pour it into a mold. This was not a perfect technique and sometimes it was necessary to repeat the heating process (García-Barneche, 2010: 21).

\footnotetext{
8 “...a royal decree from Spain dated September 14, 1519, authorized Hernán Cortés to assay, mark and affix tax stamps showing that the king's fifth had been paid on the gold and silver gathered in great quantities in the wealthy Tenochtitlán era. To carry out this decree, Cortés used the palace of Montezuma's father as a foundry, effectively the first foundry in the territory of New Spain" (García-Barneche, 2010: 20).
} 
Para 1521, Hernán Cortés tenía ya en una habitación de su casa de Coyoacán una casa de fundición en la que se acuñaban piezas en una aleación de oro de baja calidad con cobre. Como una manera de regular esta actividad y de asegurar el "quinto real".

Changes to the operation and oversight of the foundry were put into place by royal decree in 1522 with the primary change being the addition of various foundrymen who helped to consolidate the administration and to create new posts relating to specific tasks within the foundry (García-Barneche, 2010: 21).

Por supuesto que esta casa de fundición no realizaba monedas ni remotamente parecidas a las que producían las casas españolas: las piezas de forma irregular que llevaban como marca de identificación símbolos estampados a golpe de martillo eran los llamados tejuelos que fueron descritos más arriba.

Varios tipos de peso surgieron antes de que la primera casa de moneda fuera fundada en América por el Virrey Antonio de Mendoza en 1536: el peso de oro de minas fue la unidad de oro no acuñada que improvisaron los pobladores españoles de las islas sobre la base del castellano, que era más familiar para ellos; pesaba un cincuentavo de marco (4.6 gramos), con una pureza de 22.5 quilates y un valor de 450 maravedíes; el peso corriente u oro común fue el resultado de una aleación hecha por los españoles en México que estaba más cerca de los 18 que de los 21 quilates, su peso era variable y su valor era de 300 maravedíes; el peso de oro de 
tepuzque, que tenía la mezcla de cobre en mayor proporción, estaba valuado en 272 maravedíes.

Además de estas estaban otras monedas de oro acuñadas en Europa como el doblón (750 maravedíes), el castellano (500 maravedíes) y el ducado (375 maravedíes).

Como puede verse, todo este sistema de unidades monetarias era complejo, además de que la calidad de las piezas de oro no acuñadas era irregular y por lo tanto su valor real era imposible de precisar. Todo esto condujo a que la corona española decidiera establecer casas de moneda en América. Por la cédula del 11 de mayo de 1535, entregada al Virrey Antonio de Mendoza antes de su partida de España, se decretaba la creación de casas de moneda en México, Bogotá y Potosí. La acuñación de monedas de oro quedó prohibida; solo podían usarse la plata y el cobre en las condiciones que marcaba la cédula.

Volviendo al peso de oro de tepuzque, el Diccionario Porrúa de historia, biografía y geografía de México (1986, II: 2901) señala que:

El 6 de abril de 1526, el Cabildo de la ciudad de México autorizó a los dueños de esos discos a presentarlos a la Real Oficina de Fundición y Ensaye para ser fundidos en tamaños menores o mayores según su contenido en oro de minas. Siguieron, sin embargo, en circulación, sin tener valor fijo y se aceptaban a precios diferentes según la apariencia que tenían. ${ }^{9}$

\footnotetext{
${ }^{9}$ En el mismo año de 1526, el rey mandó a México al oficial español Luis Ponce de León con nuevos sellos para marcar el oro y la plata que se producían allí y con órdenes reales para el establecimiento de una casa de fundición oficial; pero eso no sucedió sino hasta una década más tarde.
} 
A la larga, Carlos $\mathrm{V}$ accedió a las peticiones que muchos colonos españoles en América le hicieron y por eso los pagos de impuestos y multas se realizaron con estos pesos de oro de tepuzque de manera que acabaran por desaparecer de la circulación. "Despite the reputation of these pieces, they served as money in the absence of proper coinage and circulated as late as the 1550s" (García-Barneche, 2010: 23).

La producción de plata comenzó a sentirse en la Nueva España, alrededor de 1530, cuando la cantidad de monedas con este mineral aumentó considerablemente. Poco después, en 1537, el Virrey Mendoza obtuvo permiso de la corona española, a través del decreto del 18 de noviembre, para acuñar monedas de plata que tuvieran el mismo valor de los pesos de oro de tepuzque, es decir, 272 maravedíes. Así surgió el peso de plata de 8 reales, llamado peso fuerte o duro real de a ocho, que fue la moneda general de circulación en todas las tierras dominadas por España. Esta moneda fue, según Clarence Haring (1975: 289), "el prototipo del dólar de plata estadounidense".

Este peso de ocho reales o 27.08 gramos de plata pura que valía 272 maravedíes, con su división en 34 maravedíes o doce granos, fue el modelo que se conservó hasta que en 1868 se introdujo el sistema decimal en la República Mexicana y se acuñaron monedas de pesos y centavos. Lo curioso es que a pesar de la adopción del sistema decimal, el peso de plata que apareció en 1869, con el diseño de una balanza y el gorro frigio en el reverso, tenía el mismo valor y el mismo peso en plata que al antiguo peso de tepuzque. 


\section{Sobre los cañones}

$\mathrm{Si}$, como hemos visto, el significado de tepuzque en el sentido de moneda de oro de baja ley es el que predomina en los registros actuales del léxico colonial, la acepción de cañones es, sin embargo, temporalmente anterior en las crónicas de la conquista de México. Bernal Díaz se demora para contarnos cómo las tropas que habían vencido a los indios en la batalla de Centla, el 25 de marzo de 1519, y se habían establecido en Tabasco esperaron unos días ahí para negociar la paz con los caciques del lugar. A Cortés se le ocurrió, para amedrentar a los jefes indígenas, disparar unos cañones, pues con ellos habían causado muchísimas bajas y mucha sorpresa en dicha batalla. Dice Bernal:

Cortés les respondió algo con gravedad, como enojado, y por nuestra lengua, Aguilar, dijo que ellos habían visto cuántas veces les había requerido con la paz, y que ellos tenían la culpa, y que ahora eran merecedores que a ellos y a cuantos quedan en todos sus pueblos matásemos, y que somos vasallos de un gran rey y señor que nos envió a estas partes, que se dice el emperador don Carlos, que manda que a los que estuvieren en su real servicio que les ayudemos y favorezcamos, y que si ellos fueren buenos, como dicen, que así lo haremos, y si no que soltará de aquellos tepuzques que los maten (y al hierro en su lengua llaman tepuzque)... (1977, I: 117-118).

Es curiosa la acotación de Bernal, pues parece olvidar la etimología que sí recuerda puntualmente más adelante en su crónica para el caso del oro adulterado. Por otra parte, el hecho de que los indígenas llamaran tepuzque al hierro 
no es sino una ampliación metafórica corriente del significado del metal que ellos conocían, el cobre, a otro cuyas características eran desconocidas para ellos; pero, ¿estaban hechos de "hierro"10 los cañones que usaron los españoles en la conquista?

George Stone (1961: 160) sostiene que los primeros cañones elaborados en Suiza ${ }^{11}$ a finales del siglo XIV eran barras de acero soldadas entre sí con bandas exteriores del mismo metal para darles mayor firmeza. ${ }^{12}$ Comenzaron a elaborarse cañones fundidos de una pieza en el siglo $\mathrm{XV}$, tanto en Italia como en Alemania, a partir de una combinación de $90 \%$ de cobre y $10 \%$ de estaño. De este bronce se elaboraron los cañones que tanto las tropas francesas como las españolas (más tarde también las inglesas) usaron en las numerosas batallas del siglo XvI.

Por la importancia que en las maniobras tácticas y estratégicas adquirieron los cañones en el campo de batalla, Carlos V dedicó mucho tiempo y esfuerzo a desarrollar una de las artillerías más importantes de la Europa de su época. Para ello convocó a los mejores especialistas y los puso a trabajar a su servicio. Así, desde "principios del siglo XvI, el

\footnotetext{
${ }^{10}$ Esta dualidad en el sentido de tepuzque permaneció en el español colonial, ya que Cecilio Robelo, en su Diccionario de aztequismos (s.f.: 261), señala que "cuando los mexicanos conocieron el fierro lo llamaron tliltic tepuztli, 'cobre negro', pero después comprendieron en la palabra tepoztli o tepuztli, el fierro, el bronce y aun el metal en general".

11 "The earliest Swiss cannon were made of iron bars welded together and strengthened by bands, later they were cast" (Stone, 1961: 160).

12 "It was not, however, until the 15 th century that they were sufficiently developed to be of much practical use except at sieges. Italy and Germany made most of the early canon, later they were made in France, but not in England until the $16^{\text {th }}$ century" (Stone, 1961: 160).
} 
artillero Luis Collado puso fin a la anarquía que reinaba respecto a los calibres y bocas de fuego existentes hasta entonces, regularizando los primeros y agrupando las segundas en tres grupos..." (González, 2000: 288). Además, "Carlos $\mathrm{V}$ hizo venir a España fundidores alemanes que trabajaron en Sevilla, ciudad de fácil acceso a los barcos que traían el inmejorable cobre de las colonias americanas" (González, 2000: 288).

De todo esto y de un largo periodo de experimentación iniciado en Bruselas surgieron los primeros criterios seguros para la fabricación de cañones en España, que se fundían con una aleación "compuesta por 92 partes de cobre y 8 de estaño" (González, 2000: 288). Así se fabricaron en Málaga doce cañones que pretendían rivalizar con los del rey francés Francisco I, el mayor rival de Carlos V, y por ello se fabricaron en un calibre y en un tamaño mayores. Según nos cuenta José Antonio González (2000: 288), el embajador veneciano que los vio escribió a su dux que eran los mejores de todo el mundo.

Con estos antecedentes tenemos ya elementos de juicio suficientes para poner el comentario de Bernal citado más arriba en un contexto de verdad que nos permita separar los errores interpretativos de la información cierta.

Cuando Hernán Cortés, después de conquistar la ciudad de Tenochtitlan, se propuso hacer unos pequeños cañones nos cuenta que:

...por algunas provincias de las de estas partes me di mucha prisa a buscar cobre, y di para ello mucho rescate, para que más aína se hallase; y como me trajeron cantidad, puse por obra con un maes- 
tro que por dicha aquí se halló, de hacer alguna artillería, e hice dos tiros de medias culebrinas, y salieron tan buenas que de su medida no pueden ser mejores; y porque aunque tenía cobre faltaba estaño, porque no se pueden hacer sin ello... (1963: 231-232).

La cita de Cortés parece confirmar lo dicho arriba y me parece que justifica el nombre de tepuzques que los indígenas dieron a los cañones de los españoles a partir de su elemento constitutivo principal.

Bernal Díaz se refiere por segunda vez a los cañones como tepuzques cuando las tropas españolas estaban a punto de marchar a Tenochtitlan, antes de la conquista, y los tlaxcaltecas le habían ofrecido a Cortés 10 mil hombres:

Cortés se lo agradeció mucho su buena voluntad, y les dijo que no es justo entrar en México con tanta copia de guerreros, especialmente siendo tan contrarios los unos de los otros; que solamente había menester mil hombres para llevar los tepuzquez y fardaje y para adobar algunos caminos. Ya he dicho otra vez que tepuzquez en estas partes dicen por los tiros, que son de hierro, que llevábamos (1977, I: 252).

Salen de Tlaxcala el 11 de octubre de 1519.

\section{Sobre la locución peyorativa}

Como hemos visto, de la acepción principal cuyo referente es el cobre, los soldados españoles ampliaron el significado y le agregaron una connotación peyorativa que provenía 
de recordar el fraude llevado a cabo con los pagos que hizo Cortés a partir de un oro adulterado convertido en moneda de baja ley y forma irregular. Al respecto nos dice Bernal Díaz:

y ahora tenemos aquel modo de hablar que cuando nombramos algunas personas que son importantes o preeminentes y de merecimiento decimos el señor don fulano de tal nombre, o Juan o Martín o Alonso; y otras personas que no son de tanta calidad les decimos su nombre, y por haber diferencia de los unos a los otros decimos fulano de tal nombre tepuzque (1977, II: 74).

Busqué minuciosamente esta locución en las obras de autores mexicanos coloniales como Sor Juana Inés de la Cruz, Carlos de Sigüenza y Góngora, Juan Ruiz de Alarcón y Fernán González de Eslava, que utilizan un léxico deliberadamente rico en mexicanismos; pero no localicé ni un solo ejemplo. ¿Sería una moda expresiva que solo cundió entre los soldados de Cortés?

Quienes sí registran esta expresión son el historiador decimonónico Lucas Alamán y el lexicógrafo moderno Luis Cabrera. El primero, siguiendo a Bernal Díaz dice: “...y fue tal el descrédito de este oro que se llamó de tepuzque, que en megicano significa cobre, que en las burlas de los soldados, acostumbraban llamar a los que de repente se habían enriquecido y querían aparentar una importancia que no tenían D. Fulano de Tepuzque" (1985, I: 118). Luis Cabrera registra en su diccionario, como tercera acepción de la palabra: "Gente de tepuzque, es decir, advenediza, con pretensiones 
de rica" (2000:134). Y en su propia imaginación, digna de alabanza, podríamos agregar.

Hasta aquí la información histórica, la parte en que se toman los referentes en su contexto real y se citan los textos coloniales para poner en evidencia los usos de la palabra tepuzque que no han llegado hasta nosotros en los repertorios actuales de mexicanismos. En los apartados que siguen, llevo a cabo un estudio semántico de la palabra, que muestra su carácter de préstamo en el español de los conquistadores y su evolución en él hacia una polisemia motivada por distintos factores tanto psicológicos como históricos.

\section{Acepciones de la palabra tepuzque en los principales diccionarios de mexicanismos ${ }^{13}$}

En el Diccionario de mejicanismos, de Francisco J. Santamaría, hay varias entradas para la palabra que nos ocupa. En la primera, donde escribe tepusque, establece la etimología del náhuatl (tepuzqui, cobre) y define la palabra en los siguientes términos: "Moneda de cobre de baja ley, usada en el país en los primeros años tiempos de la dominación española" (1992: 1036); las siguientes tres entradas son de hecho variantes de la palabra: tepuxtle, tepuxtli y tepuzque.

\footnotetext{
${ }^{13}$ Conviene aclarar que el Diccionario del español de México no es, como los diccionarios de mexicanismos, un diccionario diferencial sino un diccionario integral del español hablado en México. Si se analizó en este grupo de diccionarios fue para ampliar el parámetro del estudio del léxico usado en nuestro país actualmente.
} 
Tanto el Diccionario breve de mexicanismos, de Guido Gómez de Silva (2003), como el reciente Diccionario de mexicanismos de la Academia Mexicana de la Lengua (2010) no incluyen la palabra tepuzque, pese a que el primero de ellos declara en la introducción que "no se han excluido los mexicanismos históricos". En realidad, ambos diccionarios, al ser muestras sincrónicas de palabras limitadas al ámbito de México, solo reúnen aquellas que los hablantes mexicanos del español actual usan para comunicarse de manera regular y que los hablantes de otros países hispanohablantes desconocen.

Lo mismo puede decirse del Diccionario del español de México, que acaba de terminar después de treinta años de ininterrumpida labor un equipo de investigadores dirigido por Luis Fernando Lara en El Colegio de México y que se formó a partir de una base de datos recopilada por el propio grupo de investigadores: "Lo mejor sería reunir una gran cantidad de textos y grabaciones para sacar de ellos, imparcial y objetivamente, el vocabulario buscado" (2010, I: 19). La muestra de documentos reunidos abarcó, por decisión del consejo de redacción, el periodo histórico que va de 1921 hasta 1974.

Tampoco el flamante Diccionario de americanismos elaborado por la Asociación de Academias de la Lengua Española (2010) incluye la palabra tepuzque, pues se limita a registrar las palabras que tienen más o menos cincuenta años de antigüedad en los diferentes países americanos de habla española. 


\section{Etimología de la palabra tepuzque}

Cecilio Robelo, en su Diccionario de aztequismos, dice que tepuzque proviene del náhuatl tepuztli, que significa 'cobre'. Sobre su significado dice: "Moneda de baja ley, usada en los primeros tiempos de la dominación española. Se le dio este nombre por la gran cantidad de cobre que entraba en la liga de la moneda" (s.f.: 261).

A su vez, la palabra tepuztli proviene, según Robelo, de tepoztle, que se compone de las raíces tetl, 'piedra' y poztli, 'quebrado' o 'que se quiebra', de donde resultaría que cobre, para los aztecas, era literalmente 'piedra quebradiza'.

Por su parte, Luis Cabrera, en su Diccionario de aztequismos, dice prácticamente lo mismo: que la palabra tepuzque proviene del náhuatl tepuztli ('cobre') y que significaba: "Moneda corriente, con gran liga de cobre. Oro de tepuzque o plata de tepuzque: de baja ley..." (2000: 134).

\section{Topónimos formados a partir de la raíz náhuatl tepuztli}

Además de las acepciones analizadas en la parte histórica, existen, desde la época colonial, regiones que incluyen en su nombre la raíz que designa al cobre en la lengua de los antiguos mexicanos, seguramente porque en dichos territorios existieron en algún momento yacimientos de este mineral.

Conviene aclarar que esta parte no pretende ser de ninguna manera exhaustiva. La muestra mínima de topónimos 
incluidos aquí nos permite observar que tepuzque fue una raíz productiva en la formación de términos locativos, pues, entre los que recogí, están representados diferentes estados de la República Mexicana: Morelos, Oaxaca y Michoacán. Y aun podrían añadirse ciertas poblaciones, como Tepusco, en el estado de Jalisco, que quizá provengan de la misma raíz (su forma misma lo anuncia), aunque en este caso no pude localizar claramente la raíz de 'cobre' en ella. Ubicar claramente la raíz tepuzque fue un requisito indispensable para incluir los topónimos aquí analizados.

Nos encontramos también con un problema de análisis distinto al de los puntos anteriores. Si en aquellos podemos hablar de extensiones semánticas de una misma palabra (acepciones), aquí tenemos procesos morfológicos de derivación en los que interviene la palabra tepuzque como un elemento más (por lo general lexema) en la formación de los sustantivos. A sabiendas de esto, incluí esta parte por considerar que es de interés para comprender mejor el proceso de translación semántica que sufrió esta palabra náhuatl en el español de México durante el siglo Xvi y hasta la fecha. Pero debe quedar claro que los topónimos no son diferentes acepciones de la palabra tepuzque.

En México, la población del estado de Morelos que se sitúa a $18 \mathrm{~km}$ al noreste de Cuernavaca, llamada Tepoztlán (paroxítona en náhuatl), fue un asentamiento de los aztecas. Su construcción se terminó a más tardar en 1502, según lo atestigua una placa hallada por arqueólogos modernos. (Diccionario Porrúa, 1986, III: 2900). Gómez de Silva (2003: 222) dice que el nombre de esta población proviene del "ná- 
huatl Tepoztlan, literalmente = 'lugar abundante en cobre' [de tepoztli 'cobre; hierro' + -tlan 'lugar abundante en']".

En el diccionario que coordinó Carlos Montemayor (2008), titulado Diccionario del náhuatl en el español de México, se consignan, además de Tepoztlán, el topónimo Tepuxtepec,Santiago Domingo, situadoen el estadodeOaxaca, y que, según esta obra, significa 'en el cerro del metal'. Formado a partir de tepoz-tepe-c. "De tepoztli, metal, tépetl, cerro, -c, part[ícula] locativa”. El pueblo Santo Domingo Tepuxtepec es también un municipio que forma parte de la región de la Sierra Norte, Distrito Mixe. En la región hay también un río con el nombre de Tepuxtepec.

Hay otra localidad, llamada Salto de Tepuxtepec (Tepuxtepec), que está situada en el Municipio de Contepec, en el estado de Michoacán de Ocampo. Tiene 1875 habitantes y fue fundada en 1927; creció gracias a los trabajadores que construyeron la presa, que lleva el mismo nombre, Tepuxtepec, y la hidroeléctrica. A dos kilómetros del poblado, se halla la Central Hidroeléctrica Lerma.

También el pueblo de San Pedro y San Pablo de Teposcolula, situado en Oaxaca, "Región montañosa, con pocas corrientes de agua. Clima templado" (Diccionario Porrúa, 1986, III: 2633), es cabecera del municipio que lleva el mismo nombre. Su nombre proviene, como lo indica Gómez de Silva (2003: 222), del "náhuatl Tepozcolulan, literalmente = 'cerca de los ganchos de cobre', de tepozcoluli 'gancho de cobre' [de tepoztli 'cobre' + col- 'doblar; curva'] + -lan 'entre, junto a". Durante el siglo xvi fue el centro de comercio español en la zona mixteca. 
Erwin Gudde (1998: 390), por su parte, habla de un arroyo y sitio de tepuzque que están en Santa Bárbara, California; señala que en un mapa de 1837 que registra la zona la palabra está mal escrita (tepusquet) y recuerda que la etimología es de 'tepuztli', que significaba 'cobre' para los aztecas.

\section{La palabra tepuzque como préstamo entre los conquistadores}

Un hecho prácticamente conocido por casi todos los seres humanos es que hay numerosas lenguas en el mundo (se calculan alrededor de seis mil) y que esas lenguas se reparten de manera azarosa en los diferentes territorios. De esto surge que, cuando uno viaja a otros territorios, así sean colindantes con el propio lugar de origen, se encuentra con expresiones que desconoce y que debe aprender a usar si desea comunicarse con las personas que ahí viven. A esto hay que añadir que en esos territorios seguramente existen objetos desconocidos para el viajero, que este llega a conocer junto con la palabra o expresión que los locales usan para referirse a aquellos. Por esta razón, como afirma Ronald L. Trask: "everybody is in a position to learn some of the words used by their neighbors, and very frequently people take a liking to some of their neighbors words and take those words over into their own language" (1996: 18).

A este proceso de tomar palabras de otra lengua para incorporarlas a la propia se conoce como préstamo (borrowing en inglés) y, en palabras de Ronald Trask: "is one of the most 
frequent ways of acquiring new words, and speakers of all languages do it" (1996: 18).

En su expedición, Hernán Cortés se valió de algunos intérpretes (Julián, Melchor, Francisco, Jerónimo de Aguilar y la Malinche ${ }^{14}$ para establecer comunicación con los indígenas americanos y seguramente a través de ellos fueron llegando a los españoles, como préstamos, las palabras procedentes del maya y del náhuatl, que antes eran indescifrables para los conquistadores.

Cómo y cuándo se tomó prestada la palabra tepuzque por los conquistadores es difícil saberlo, pues sería necesaria más documentación anterior y simultánea a las crónicas de la conquista que han llegado hasta nosotros. Pero no hay duda de que el léxico indígena de origen americano está presente en las obras de los escritores españoles del siglo XVI, pues Rafael Lapesa sostiene que:

La adopción de léxico aborigen empezó en los años mismos de los descubrimientos y primeras instalaciones de españoles: el Diario de Colón recoge voces taínas [...] el historiador y naturalista Fernández de Oviedo (1535-1557) emplea o menciona más de 500 americanismos [...] Bernal Díaz del Castillo usa ochenta y tantos, Juan de Castellanos 155, y el corpus de documentación municipal

\footnotetext{
${ }^{14}$ Cuenta Bernal Díaz que "con los indios Julianillo y Melchorejo, que trajimos cuando lo de Francisco Hernández, que entendían muy bien aquella lengua, les habló" (1977, I: 61). Más adelante dice: "Y allí traíamos otra lengua que se decía Francisco, que hubimos cuando lo de Grijalva” (1977, I: 120). En Cozumel, narra Bernal que "en dos días les dieron a un español que se decía Jerónimo de Aguilar...” (1977, I: 98). Los caciques de Tabasco dieron a Cortés un regalo que, entre otras cosas incluía "veinte mujeres, y entre ellas una muy excelente mujer que se dijo doña Marina” (1977, I: 119).
} 
y judicial reunido para el Léxico hispanoamericano del siglo xvi de Peter Boyd-Bowman contiene 229... (1988: 558).

¿Por qué los hablantes de una lengua particular toman préstamos de otras lenguas? Los préstamos pasan de una lengua a otra por tres razones principales: necesidad, prestigio y para expresar una valoración despectiva.

A la necesidad me he referido ya más arriba. Sobre esta, Lyle Campbell sostiene que: "When speakers of a language acquire some new item or concept from abroad, they need ${ }^{15}$ a new term to go along with the new acquisition; often a foreign name is borrowed along with the new concept" (2004: 64).

El prestigio tiene que ver con el desarrollo cultural o tecnológico de ciertas naciones o grupos de personas durante una época en particular, lo cual provoca que los productos de esa sociedad se vuelvan atractivos para los demás independientemente de que la lengua receptora tenga palabras para denominar la misma cosa. En este sentido, se toman palabras de otra lengua "because the foreign term for some reason is highly esteemed. Borrowings from prestige are sometimes called 'luxury' loans" (Campbell, 2004: 64).

A veces ocurre también que, aunque los hablantes de una lengua tengan palabras para referirse a un concepto o a un objeto, toman una palabra prestada de otra lengua para esa misma realidad porque el término extranjero les resulta más expresivo. "Some loans involve a third, much rarer (and much less important) reason for borrowing, the opposite of prestige: borrowing due to negative evaluation,

${ }^{15}$ Las cursivas son de Lyle Campbell. 
the adoption of the foreign word to be derogatory". ${ }^{16}$ (Campbell, 2004: 65).

Llegados a este punto vale la pena preguntarnos: ¿por qué razón los conquistadores españoles tomaron prestada la palabra tepuzque del náhuatl? No parece haber razones de necesidad, pues el cobre era un metal conocido en la Europa de esa época (la palabra que usamos en español para referirnos a este metal proviene desde el griego). ${ }^{17}$

¿Pudo haber sido por prestigio? Parece difícil sostener este punto de vista, pues los españoles de las primeras expediciones no tenían ni mucho interés ni mucha capacidad lingüística ${ }^{18}$ para apreciar las lenguas indígenas americanas y no valoraban mucho sus costumbres ni sus logros culturales. Aunque después los misioneros escribieron numerosas gramáticas y diccionarios de dichas lenguas, su interés era predominantemente castellanizador y evangelizador: si se interesaron en sus lenguas fue para convertirlos a su lengua y a su cultura europea de rancio catolicismo medieval.

Si no fue ni la necesidad ni el prestigio, entonces la opción restante (por eliminación) es que los españoles tomaron la palabra náhuatl para expresar una valoración negativa que se transmitió a través de ciertas expresiones peyorativas. Esta hipótesis parece fortalecerse si recordamos que las

\footnotetext{
${ }^{16}$ Las cursivas son de Lyle Campbell.

17 Corominas (1987: 155) señala como fecha de primera aparición de esta palabra en español alrededor de 1220-1250. Proviene del lat. Cŭprum y esta a su vez del griego Kýpros.

${ }^{18}$ Al hablar del duro oído que tenían los conquistadores, Lope Blanch dice: "Cuya extrema dureza — torpeza- auditiva les impedía registrar fielmente las voces de las lenguas indoamericanas, y causaba que éstas quedaran monstruosamente alteradas en los documentos escritos por aquéllos" (2003: 99).
} 
monedas llamadas tepuzques eran de acuñación fraudulenta (menos oro del debido) y que a las personas falsas se les denominó también "de tepuzque". Solo en el caso de los cañones no parece haber ningún matiz despectivo.

\section{Transformaciones fonéticas y morfológicas de la palabra tepuzque}

Cuando los préstamos ingresan a la lengua que los toma, pueden sufrir cambios: "Borrowed words are usually remodelled to fit the phonological and morphological structure of the borrowing language, at least in early stages of language contact" (Campbell, 2004: 64).

En el caso de la palabra tepuzque, podemos observar algunos cambios debidos a su paso al español. Como vimos en el apartado 6, la palabra tepuzque proviene del náhuatl tepuztli, que significa cobre. Esta última forma es la que los españoles debieron haber oído de boca de los indígenas con los que primero entraron en contacto.

Si partimos del inventario sonoro, el grupo náhuatl $T L$ es un dígrafo que representa a un fonema africado, lateral y alveolar. Al hablar de las consonantes, señala Garibay que hay "una africativa lateral, análoga a la combinación TL, con la cual es representada" (1999: 23).

Pero, como morfema, el sufijo -TLI se usa en náhuatl, desde tiempos clásicos, para formar sustantivos singulares. En esta función, equivale enteramente al sufijo -NI. Y ambos equivalen (son sufijos primarios en la formación de sustantivos en náhuatl), según Ángel María Garibay, a “un deter- 
minativo análogo al artículo de las lenguas europeas de la rama indo-germánica” (1999: 52). El sufijo -TLI se conserva inmutable si lo precede una consonante (tochtli = conejo, $\mathrm{mi}$ chtli = pez) y solo cambia si lo precede vocal (atl = agua, tetl = piedra $)$ o $L$ (calli = casa, tlalli = tierra o suelo). En el primer caso se apocopa y, en el segundo, se asimila al sonido lateral de $L$ (Garibay, 1999: 53).

El sustantivo en náhuatl puede modificarse en su morfología para expresar el número gramatical. Según Garibay (1999: 59), uno de los procedimientos que se usan para construir el plural es a través de la sustitución el sufijo primario -TL por alguno de los siguientes alomorfos: $-M E$, -TIN, -QUE (teopixqui = gran sacerdote $>$ Teopixque = grandes sacerdotes, nenemi $=$ caminar $>$ nenenque $=$ caminantes). Entonces, la palabra tepuzque pasó al español en plural, cosa extraña porque "solo forman plural los sustantivos que designan seres animados, o que se conciben como tales" (Garibay 1999: 58).

Lo anterior me permite hacer algunas afirmaciones fundamentadas: 1. El fonema lateral africado sordo / t $1 /$ no tiene equivalente en español, y, por lo tanto, es de difícil pronunciación para los hispanohablantes no mexicanos, incluso en la actualidad. El más cercano en nuestra lengua sería el palatal africado sordo /ĉ/. Por tanto, esperaríamos que los soldados españoles hubieran adaptado el náhuatl al sistema fonológico del español con la forma *tepuzche o *tepuzchi; 2. Pero, en lugar de eso, tomaron la forma plural (no tepuztli, sino tepuzque) porque coincidía con otros sustantivos del español que terminan en la misma forma -QUE. Por tanto, al parecer, un proceso de analogía morfológica entre las 
dos lenguas que estaban en contacto durante el proceso de la conquista de México.

Además, por lo que respecta a la i final del singular en náhuatl, iba en contra de la tendencia general que estas vocales, desde el latín, siguieron en el español medieval: su relajación "explica el que tres sonidos diferentes en la sílaba tónica, dos en la átona general, se reducen a uno solo en la final; es decir, todas las vocales de la serie anterior se reducen a una sola..." (Menéndez Pidal, 1987: 79).

Todo lo anterior puede verse en los resultados que obtuvo Beatriz Arias al analizar la adaptación de voces indígenas que pasaron al español de México en el siglo xvi: el fonema lateral, africado y sordo [tl], en posición final, "se puede sustituir por la combinación española cli, que es la forma castellana más cercana al sonido indígena, o que...” (1997: 153); por lo que respecta al fonema náhuatl -c, "que designa lugar, generalmente aparece en nuestros documentos con una $-e$ final añadida. Actualmente este sufijo se mantiene en México sin adición de vocal" (1997: 157).

\section{Esquema evolutivo de los significados de la palabra tepuzque}

A continuación presento un esquema que compendia de manera gráfica las acepciones de la palabra tepuzque. Para explicar este esquema voy a recurrir a la teoría semántica sobre las relaciones léxicas, de manera que dichas relaciones nos permitan ir viendo cómo evolucionaron las distintas acepciones 
desde el náhuatl hasta el español hablado por los conquistadores que encabezó Hernán Cortés. ${ }^{19}$

Conviene aclarar que este esquema no pretende ser un prototipo en el sentido que esto tiene dentro de las investigaciones que se llevan a cabo en la semántica léxica de tendencia cognitiva. Para ese tipo de investigación sería necesario establecer una serie de relaciones, entre las diferentes acepciones de tepuzque, que no son posibles aquí dada la diversidad de lenguas y la disparidad de procesos lingüísticos que fueron empleados por los hablantes de ambas lenguas para formar las palabras y asignarles un significado.

Afirma Cruse que hay algo de paradójico en la noción de relaciones semánticas entre unidades léxicas cuyos significados, al menos desde la perspectiva del contexto en que aparecen, están construidos parcialmente por esas mismas relaciones; pero lo mismo sucede cuando decimos algo sobre el brazo de Juan o la pieza del coche, pues es claro que el brazo es parte de Juan y la pieza es parte del coche.

En este sentido, nuestro conocimiento fenomenológico de las cosas nos ayuda siempre a entender que el todo es más que un mero ensamblaje de las partes. Y, por eso, "The same

\footnotetext{
${ }^{19}$ Aclaro aquí que consulté todas las crónicas de la conquista de México, tanto las de soldados que estuvieron presentes en los hechos que narran (Cortés, Bernal Díaz, Andrés de Tapia... hasta la del llamado Conquistador Anónimo) como las que se compilaron después, en época inmediatamente posterior (López de Gómara, Cervantes de Salazar, Antonio de Solís, Argensola...), hasta las salidas de la pluma de investigadores modernos (Orozco y Berra, José Luis Martínez, Hugh Thomas...). En ninguna de ellas se mencionan los usos de la palabra que menciona Bernal Díaz, pero, como no se trata aquí de fijar la frecuencia de uso ni la amplitud del mismo durante el siglo XVI, sino solo de documentar su carácter de préstamo transitorio en el español, me pareció innecesario y engorroso incluir todo ese material en la bibliografía.
} 
is true of the meanings of lexical units: each one consists of an indefinite number of contextual relations but at the same time constitutes a unified whole" (Cruse, 1997: 84).

Las relaciones contextuales de significado son de dos tipos: paradigmáticas y sintagmáticas. Las primeras son las que utilizaré a continuación para el análisis de las acepciones de la palabra tepuzque y reflejan

the way infinitely and continuously varied experienced reality is apprehended and controlled through being categorised, subcategorised and graded along specific dimensions of variation. They represent systems of choices a speaker faces when encoding his message (Cruse, 1997: 86).

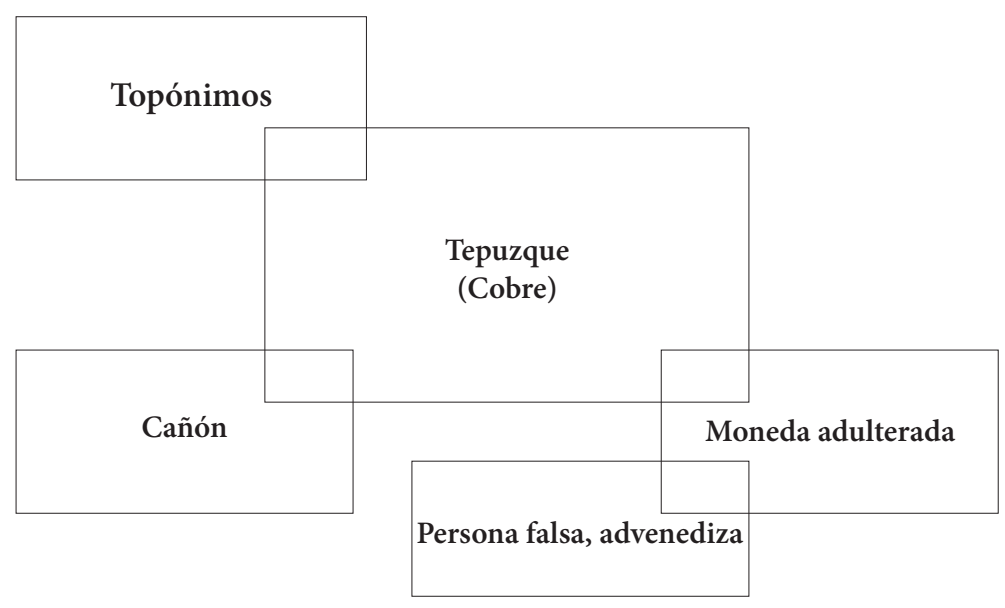

Esquema 1

Hay cuatro relaciones básicas entre las clases que forman un conjunto de variantes sistemáticas dentro del siste- 
ma de sustituciones paradigmáticas (Cruse, 1997: 86-87): 1) la identidad consiste en que tanto la clase A como la B tienen los mismos elementos (se representa con un solo cuadro en el que están A y B);2) la inclusión es en la que la clase B en su totalidad forma parte de A (se representa con dos cuadros, uno dentro del otro); 3) la intersección es en la que tanto la clase A como la clase B tienen algunos elementos en común, pero cada uno tiene elementos que no se encuentran en el otro (se representa con dos cuadros que solo comparten una sección de su superficie) y 4) la exclusión, en la que las clases A y B no tienen elementos en común.

Si trasladamos esos criterios al esquema 1, podemos ver que no hay ninguna inclusión (el sentido etimológico en náhuatl de tepuzque es independiente de las acepciones en español), es decir, que todas son de intersección: con algunas características comunes en cuanto al significado, pero con otros elementos de sentido que no comparten ambas acepciones.

Para llevar un orden lógico, comienzo por señalar las relaciones de significado de tepuzque en la lengua náhuatl. En el apartado 6, quedó dicho que 'cobre', la acepción básica, era una 'piedra quebradiza' para los indígenas. Esto implica que 'cobre' incluía en su significado, para los hablantes del náhuatl, los rasgos semánticos de 'piedra' más la fragilidad en su estructura. Pero sabemos que no todas las piedras contienen cobre. 'Piedra' es entonces el hiperónimo de 'cobre'. Para Cruse (1997: 89) hay hiperonimia cuando "...by the same token, $\mathrm{Y}$ a superordinate ${ }^{20}$ of $\mathrm{X}$ if $\mathrm{A}$ is $f(\mathrm{X})$ entails but is not

${ }^{20} \mathrm{El}$ destacado en negritas es del autor de la cita. 
entailed by A is $f(\mathrm{Y})$ ". Es decir, que 'piedra' implica a 'cobre' en su sentido de mineral, pero, como contiene también otros minerales, no puede quedar totalmente contenida en el sentido de 'cobre'.

Ya en español, surgen las extensiones de tepuzque como metonimias tanto de los cañones como de las monedas, pues ambos tienen, como parte de su composición, este metal. Para Lyle Campbell, "metonymic changes typically involve some congruity in the real (non-linguistic) world. They involve shift in meaning from one thing to another that is present in the context..." (2004: 257).

Las acepciones de monedas y cañones no presentan entonces problemas en cuanto a la atribución de cierto rasgo (tener cobre en su composición) que es necesario y suficiente dentro del contexto real para ser parte del esquema 1 a manera de intersecciones metonímicas. Están situadas en la misma jerarquía dentro del esquema (en el primer nivel radial a partir del centro) por compartir un rasgo semántico (el cobre), pero se diferencian en los demás. En ambos casos hay un estrechamiento del significado (de metal, sustantivo abstracto no contable, a algo más concreto como son las monedas y los cañones) y además se añade un matiz peyorativo al significado de la moneda, como ya vimos, por tener menos oro del que debía tener.

El caso de la locución peyorativa, que significa 'persona falsa o advenediza' es diferente a las anteriores, ya que no deriva inmediatamente del significado de cobre, sino del significado de 'falso o adulterado' contenido en la moneda. En un primer momento los hablantes identificaron las falsas monedas de oro con el cobre que las componía y en una eta- 
pa posterior la cualidad de 'falso', perteneciente a dichas monedas, se atribuyó a las personas que aparentaban ser lo que no eran, es decir, que eran falsas. La extensión se muestra en el siguiente esquema:

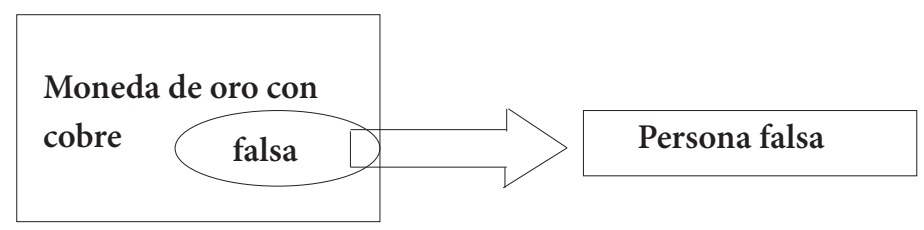

Esquema 2

En el caso de la locución peyorativa no puede definirse a una persona falsa partiendo del cobre como elemento presente en su composición, por lo que debemos acudir en este caso a otro rasgo o atributo definitorio (la falsedad) que se proyecta metafóricamente de una moneda a un individuo. Por eso, en el esquema 1 queda como extensión intersectada con la de moneda. "Metaphor in semantic change involves extensions in the meaning of a Word that suggest a semantic similarity or connection between the new sense and the original one. Metaphor is considered a major factor in semantic change" (Campbell, 2004: 256).

Por último, los topónimos se explican aquí y se conservan en el esquema 1 porque comparten el significado de cobre (tepuztli) en su estructura (es el lexema de la palabra) no por sus relaciones semánticas que produjeron extensiones en el sentido. En la estructura morfológica del náhuatl, los sufijos - TLAN y -C se utilizan (desde entonces hasta la fecha) como partículas locativas para derivar sustantivos que designan nombres de lugares. 


\section{Conclusiones}

Con todo lo dicho, he demostrado que la palabra tepuzque tuvo mucha mayor vitalidad en el siglo XVI, para los hablantes del español en México, de la que podrían hacernos pensar los escuetos datos que registran los diccionarios de mexicanismos, incluso aquellos que registran usos pertenecientes a épocas pasadas.

Pero hay que aclarar, sin embargo, que los diccionarios de nahuatlismos constituyen un tipo de diccionario de mexicanismos que solo consigna los mexicanismos genéticos o históricos procedentes del náhuatl, mientras que los diccionarios de mexicanismos, además de estos, tratan los de uso diferencial y los de ámbito objetivo o de realidades exclusivas. En este sentido, los diccionarios de aztequismos o nahuatlismos ofrecen información importante para testimoniar el uso de este tipo de mexicanismos.

Basar la aparición de un préstamo en solo dos crónicas de la conquista de México (solo en estas aparece) equivale a lo que hoy en día se conoce como investigación cualitativa, en la que no es necesario entrevistar, por ejemplo, a una población entera para saber cuáles son sus motivaciones al realizar cualquier cosa que el investigador quiera saber. En este sentido, Bernal Díaz es el informante que nos cuenta el paso de una palabra náhuatl al español y los diferentes significados que adquirió. ¿Qué motivó a los conquistadores a usar esta palabra en los sentidos que la usaron? La respuesta es este artículo.

Y esa motivación desapareció poco después, porque las acepciones estudiadas en este artículo, salvo la de moneda, 
ya no en el sentido de falsa sino de cobre, desaparecieron del español mexicano. Al menos del que nos ha legado la tradición cultural en forma de documentos escritos.

Los datos históricos incluidos en el artículo no son un mero decorado de erudición, sino que pretenden mostrar cómo el significado de cobre, presente en casi todas las acepciones de la palabra tepuzque, tuvo una razón de ser para los hablantes del español en México durante el siglo xvi. En términos lingüísticos, podemos decir que esta parte nos proporciona los referentes necesarios para el análisis diacrónico del significado de la palabra; sin ellos, la especulación sin fundamentos podría abrirse paso fácilmente.

La presentación de las diferentes acepciones de la palabra tepuzque en un esquema que se basa en las relaciones semánticas nos ayuda a entender mejor cómo surgieron estas a través del tiempo. Si no tuviéramos, por ejemplo, el antecedente de la moneda falsa que acuñó Cortés durante el proceso de la conquista y nos encontráramos de pronto en un texto la locución peyorativa dirigida a una persona, no sabríamos dónde situarla dentro del vocabulario del español aunque pudiéramos deducir su sentido (negativo) por el contexto.

Dentro del esquema propuesto, las palabras de denominaciones locativas que derivan del sustantivo tepuzque no son, en sentido estricto, acepciones de esa palabra, sino formaciones léxicas; pero, incluirlas en el esquema nos proporciona, aunque desde una perspectiva lingüística diferente (la morfológica), elementos para conocer mejor el alcance de este término que tomaron prestado los hablantes del español en el siglo XVI. 


\section{Bibliografía}

Academia Mexicana de la Lengua (2010), Diccionario de mexicanismos, México, Academia Mexicana y Siglo XXI.

Alamán, Lucas (1985), Disertaciones sobre la historia de México. Hernán Cortés y la conquista de México, 2 vols., México, Jus.

Arias Álvarez, Beatriz (1997), "Sobre la transliteración de voces indígenas durante la primera mitad del siglo xvI", en La Experiencia Literaria, marzo, pp. 151-162.

Asociación de ACademias de la Lengua Española (2010), Diccionario de americanismos, Lima, Santillana.

Cabrera, Luis (2000), Diccionario de aztequismos, México, Colofón.

CAmpbell, Lyle (2004), Historical Linguistics: An Introduction, Cambridge, Massachusetts, The MIT Press.

Corominas, JoAn (1987), Breve diccionario etimológico de la lengua castellana, Madrid, Gredos.

Cortés, Hernán (1963), Cartas y documentos, edición de Mario Hernández Sánchez Barba, México, Porrúa.

Cruse, D.A. (1997), Lexical semantics, Cambridge, Cambridge University Press.

Díaz del Castillo, Bernal (1977), Historia verdadera de la conquista de la Nueva España, edición de Joaquín Ramírez Cabañas, 2 vols., México, Porrúa.

Diccionario Porrúa de historia, biografía y geografía de México (1986), 3 vols., México, Porrúa. 
García-Barneche, Agustín (2010), The "Tumbaga" Saga:

Treasure of the Conquistadors, Winter Park, Florida, Published by Daniel Frank Sedwick, LLC.

Garibay K., Ángel María (1999), Llave del náhuatl, México, Porrúa (Colección Sepan Cuántos, 706).

Gómez de Silva, Guido (2003), Diccionario breve de mexicanismos, México, Academia Mexicana y Fondo de Cultura Económica.

GonzÁlez, José Antonio (2000), "Medio cañón bastardo", en Sociedad Estatal para la Conmemoración de los Centenarios de Felipe II y Carlos V (eds.), Carlos V. Las armas y las letras, Granada, Universidad de Granada/ Fundación ICO.

Gudde, Erwin G. (1998), California Place Names: The Origin and Etymology of Current Geographical Names. A Revised Version of 1,000 California Place Names, $3^{\text {a }}$ ed., University of California Press. Disponible en versión digital en http://books.google.com/books.

Haring, Clarence Henry (1975), The Spanish Empire in America, Orlando, Harvest-Harcourt Brace Jovanovich Publishers.

LAPEsa, Rafael (1988), Historia de la lengua española, Madrid, Gredos.

Lara, Luis Fernando (ed.) (2010), Diccionario del español de México, 2 vols., México, El Colegio de México.

Lope Blanch, Juan M. (2003), Cuestiones de filología hispanoamericana, México, Universidad Nacional Autónoma de México.

Menéndez Pidal, Ramón (1987), Manual de gramática histórica española, Madrid, Espasa Calpe. 
Montemayor, Carlos (coord.) (2008), Diccionario del náhuatl en el español de México, México, Gobierno de la Ciudad de México y Universidad Nacional Autónoma de México.

Real Academia Española, Banco de datos (CORDE) [en línea]. Corpus diacrónico del español <http://www.rae. es> [03/08/2010].

Robelo, Cecilio (s.f.), Diccionario de aztequismos, $3^{\text {a }}$ ed., México, Fuente Cultural.

Santamaría, Francisco J. (1992), Diccionario de mejicanismos, México, Porrúa.

Seco, Manuel (2003), Estudios de lexicografía española, Madrid, Gredos.

Sedwick, Dan, "Tepuzque gold, first American gold coin”. Disponible en http://www.anythinganywhere.com/ commerce/coins/tumbatxtl.htm.

Stone, George Cameron (1961), A Glossary of the Construction, Decoration and Use of Arms and Armor in all Countries and in all Times, Nueva York, Jack Brussel.

Trask, Ronald L. (1996), Historical Linguistics, Londres, Arnold. 